Article

\title{
Raltegravir Inclusion Decreases CD4 T-Cells Intra-Cellular Viral Load and Increases CD4 and CD28 Positive T-Cells in Selected HIV Patients
}

\author{
Gaurav Kumar 1,2,*(D), Jacqueline Cottalorda-Dufayard ${ }^{3}$, Rodolphe Garraffo ${ }^{4}$, Francine De Salvador-Guillouët ${ }^{5}$, \\ Eric Cua ${ }^{5}$ and Pierre-Marie Roger $1,5,6$
}

1 Unité 576, Centre Hospitalier Universitaire de Nice, Institut National de la Sante et de la Recherche Medicale, Universite de Nice-Sophia-Antipolis, 06200 Nice, France; pierre-marie.roger@chu-guadeloupe.fr

2 Arthritis and Clinical Immunology, Oklahoma Medical Research Foundation, Oklahoma City, OK 73104, USA

3 Virologie, Hopital l'Archet 2, Centre Hospitalier Universitaire de Nice, Universite de Nice-Sophia-Antipolis, 06200 Nice, France; Dufayard.J@chu-nice.fr

4 Pharmacologie, Hopital Pasteur, Centre Hospitalier Universitaire de Nice, Universite de Nice-Sophia-Antipolis, 06200 Nice, France; Rodolphe.Garraffo@unice.fr

5 Infectiologie, Hopital l'Archet 1, Centre Hospitalier Universitaire de Nice, Universite de Nice-Sophia-Antipolis, 06200 Nice, France; guillouet.f@chu-nice.fr (F.D.S.-G.); cua.e@chu-nice.fr (E.C.)

6 Service Des Maladies Infectieuses et Tropicales, Centre Hospitalier Universitaire de Pointe-à-Pitre, 97159 Pointe-à-Pitre, France

* Correspondence: Gaurav-kumar@omrf.org; Tel.: +1-(405)-271-2907; Fax: +1-(405)-271-4110

check for

updates

Citation: Kumar, G.;

Cottalorda-Dufayard, J.; Garraffo, R.; De Salvador-Guillouët, F.; Cua, E.; Roger, P.-M. Raltegravir Inclusion Decreases CD4 T-Cells Intra-Cellular Viral Load and Increases CD4 and CD28 Positive T-Cells in Selected HIV Patients. Cells 2022, 11, 208. https:// doi.org/10.3390/cells11020208

Academic Editor: Alessandro Poggi

Received: 26 November 2021

Accepted: 30 December 2021

Published: 8 January 2022

Publisher's Note: MDPI stays neutral with regard to jurisdictional claims in published maps and institutional affiliations.

Copyright: (C) 2022 by the authors. Licensee MDPI, Basel, Switzerland. This article is an open access article distributed under the terms and conditions of the Creative Commons Attribution (CC BY) license (https:// creativecommons.org/licenses/by/ $4.0 /)$.

\begin{abstract}
Raltegravir (RLT) prevents the integration of HIV DNA in the nucleus, but published studies remain controversial, suggesting that it does not decrease proviral DNA. However, there are only a few studies focused on virus-targeted cells. We aimed our study on the impact of RLT inclusion on total intra-cellular viral DNA (TID) in cellular subsets and immune effects in patients with newly acquired undetectable plasmatic viral load (UVL). Six patients having UVL using an antiretroviral combination for 6 months and CD4 T-cells $>350 / \mathrm{mL}$ and $<500 / \mathrm{mL}$ were selected to receive RLT for 3 months from M0 to M3. Patients had 7 sequential viro-immunological determinations from M-1 to M5. Immune phenotypes were determined by flow cytometry and TID quantification was performed using PCR assay on purified cells. TID (median values) at the initiation of RLT in CD4 T-cells was 117 copies/millions of cells, decreased to 27.5 on M3, and remained thereafter permanently under the cut-off ( $<10$ copies/millions of cells) in 4 out of 6 patients. This was associated with an increase of CD4 and CD4 + CD28+ T-cells and a decrease of HLA-DR expression and apoptosis of CD4 T-cells. RLT inclusion led to decreases in the viral load along with positive immune reconstitution, mainly for CD4 T-cells in HIV patients.
\end{abstract}

Keywords: HIV infection; raltegravir; CD4 T-cells; pharmacokinetics; viral load

\section{Introduction}

The morbidity and mortality related to Human Immunodeficiency Virus (HIV) infection have dramatically decreased in countries where antiretroviral combinations are available [1]. A better clinical outcome is usually seen in HIV patients that receive antiretroviral therapy (ART) in the early phase of viral infection following HIV diagnosis [2]. Most of the time, undetectable viral load is reached within a few months after the beginning of ART, which is associated initially with a rapid rise in CD4+ T-cell followed by a subsequently slower increase over the years of treatment [3]. However, a major limitation of ART lies in the fact that it is still incapable of completely restoring the normal immune response which could suppress viral replication after ART has been stopped [4].

To date, preventing the establishment of the viral reservoir and its replication has been a major limitation, even after several years of ART [5]. CD4+ T-cells and monocyte-lineage 
are the most important targets for HIV-1. These cells are the main cellular reservoirs in which the virus can persist and survive for long periods within the body [6-8]. These two different T-cell types may help in continuous replication of the virus despite efficient ART $[9,10]$. Viruses infect activated CD4 T-cells that are transitioning back to the resting memory state. The stably integrated provirus remains transcriptionally inactive in the longlived memory T-cells thereby evading host immune response and ART [11]. HIV viruses infect circulating monocytes which further differentiate into macrophages. These infected macrophages contribute significantly to viremia during ART, as the viral replication in CD4 T-cells is inhibited [12]. Cellular reservoirs and tissue sanctuaries allow continuous low-level viral transcription and contain integrated proviral DNA despite continuous ART $[13,14]$. These data necessitate the search for an efficient ART with potential to eliminate the cellular provirus for a sustained therapeutic benefit.

T-cell activation has been reported to be a predictor of HIV disease progression and can even predict ART treatment failure [13]. HIV viruses specifically target the T-cells by exploiting the costimulatory molecules CD28 and CTLA-4, resulting in the excessive loss of CD4 T-cells with an increase in CD8 T-cells and HIV infection. This is reported in part through down-regulation of CD28 expression and overexpression of CD152 [14-17]. Expression of these two abnormal membrane-bound proteins is associated with enhanced T-cell apoptosis, a hallmark of HIV infection [18,19]. Additionally, downregulation of CD80 and CD86 markers on T-cells occurs during HIV infection, which greatly impedes T-cell function in eliminating viral replication $[20,21]$. Given the active role of the interaction between CD28/CD152-CD80/CD86 for antigen presentation and development of an effective immune response, it might be possible that the HIV virus evades this pathway for its replicative benefits [22]. Excessive cellular activation and alterations of numerous membrane proteins such as costimulatory molecules, including CD28 and CD152, are still detected [15-17,23-25]. These results imply persistent perturbations of homeostasis at the cellular level despite efficient ART.

Raltegravir (RLT) is a potent HIV-1 integrase inhibitor, restraining the HIV-DNA integration into the host genome [26-28]. Although RLT has been reported to rapidly improve the CD4 and CD8 T-cell count, the associated immunological recovery has not been reported so far $[29,30]$. Therefore, we investigated the hypothesis that the inclusion of RLT might decrease the intracellular reservoir, and as a result, improve the T-cell homeostasis by modulating the costimulatory pathway.

Our study was aimed to measure the impact of RLT on the intra-cellular viral reservoir, in both lymphocytes and monocytes, and to measure the impact of this treatment on T-cell homeostasis, with emphasis on costimulatory molecules. We also sought to determine the RLT concentrations in purified cells, as there are only very few reports on pharmacokinetic measurements of RLT inside the HIV-targeted immune cells (i.e., CD4 T-cells and monocytes).

\section{Materials and Methods}

\subsection{Study Subjects}

Six HIV-infected patients attending the Infectious Disease Department of Nice University Hospital, France, were recruited for this prospective study (5 males, 1 female, age range 31-65 years old). This study was realized in accordance with the ethical committee of our institution and the patients gave their informed consent in compliance with our institutional review board.

The inclusion criteria were to be infected with HIV-1, presenting with an undetectable viral load for at least 6 months and a CD4 T-cell count between 350 and 500 CD4 T-cells $/ \mathrm{mm}^{3}$, using ART based on two nucleoside reverse transcriptase inhibitor (NRTI) and one protease inhibitor (PI) for no more than one year.

RLT was added to the ART combination of the patient for 3 months (400 mg twice daily). Two samples were taken before adding RLT, and two after stopping it, allowing the 
study of 7 consecutive time points i.e., day -30 and day 0 (before RLT intake); day 30, day 60, and day 90 (during RLT intake); and day 120 and day 150 after RLT withdrawal.

The exclusion criteria included previous use of an integrase inhibitor, patients with active opportunistic infection and/or cancer as well as those patients who benefited from recombinant IL-2, interferon- $\alpha$, steroids, or other medications known to modify immune cell reactivity.

\subsection{Sample Processing, Cell Separation, and Cell Culture}

Blood samples were drawn from patients in tubes containing acid citrate dextrose (ACD) in the Infectiologie unit of the hospital and brought to the lab immediately for processing. Whole blood was centrifuged to obtain the plasma. Peripheral blood mononuclear cells (PBMCs) were isolated from the blood using Ficoll-Paque PLUS (Stemcell Technologies, Vancouver, BC, Canada) density gradient centrifugation. For analysis of phenotypic and functional markers, PBMCs were used immediately after their isolation and counting. To observe the alteration in proliferation and apoptosis, T-cells were stimulated overnight with CD3 and CD28 at $37^{\circ} \mathrm{C}$ with 5\% CO 2 in RPMI 1640 (Gibco, Grand Island, NY, USA) supplemented with $10 \%$ of fetal calf serum (Thermo Fisher Scientific, Hampton, NH, USA). For separation of CD4 T-cells and monocytes from PBMC, we used positive (monocytes) and negative (CD4 T-cells) magnetic separation kits (Stemcell Technologies, Vancouver, BC, Canada), and the purity of the cells was verified by flow cytometry. After counting, the cells were stored as pellets along with plasma and $\mathrm{PBMC}$ at $-80^{\circ} \mathrm{C}$ for viral load and pharmacological analysis. All the purification steps were performed at $4{ }^{\circ} \mathrm{C}$ in order to prevent drug loss from the cells.

\subsection{Cell Stimulation with CD3/CD28}

Cell culture was performed in coated wells with anti-CD3 mAbs and anti-CD28 mAbs added in solution (clone 28-2, $10 \mu \mathrm{g} / \mathrm{mL}$ final dilution). Wells were coated as follows: $500 \mu \mathrm{L}$ of medium containing CD3 mAbs (clone X3,10 $\mu \mathrm{g} / \mathrm{mL}$ final dilution), incubated for $2 \mathrm{~h}$ at $37^{\circ} \mathrm{C}$; wells were then washed 3 times with the medium alone. Clone X3 and 28-2 are produced in our laboratory.

\subsection{Monoclonal Antibodies}

The following conjugated Anti-human monoclonal antibodies (mAbs) were purchased from BD Pharmingen, USA: CD3 PE-Cy7, CD4 FITC, CD4 PerCP-Cy5.5, CD4 APC, CD8 PerCP-Cy5.5, CD14 PerCP-Cy5.5, CD14 PE, CD80 FITC, CD86 PE, CD152 PE, HLA-DR APC, Ki67 PE, Annexin V FITC, and Propidium Iodide. CD28 FITC and CD45 Pacific blue were purchased from eBioscience, USA.

\subsection{Multiparameter Flow Cytometry}

For the extracellular labeling of the cells, one million PBMCs were taken in each tube, and antibodies were added to it. Thereafter, cells were incubated at $4{ }^{\circ} \mathrm{C}$ in the dark for 20-30 min, washed twice with PBS, and analyzed using flow cytometry (FACS CANTO II, BD Biosciences, NJ, USA) within $24 \mathrm{~h}$ of labeling. For intracellular labeling (Ki67), the cells were firstly labeled with extracellular antibodies, washed in PBS, fixed, and permeabilized. Lastly, cells were stained with $\mathrm{mAbs}$ along with an isotype-matched control mAbs (Becton Dickinson, San Jose, CA, USA). We used cytofluorometric techniques with a six-color labeling pattern (FITC/PE/PerCP-Cy5.5/PE-Cy7/APC/Pacific blue).

\subsection{Viral Load Analysis}

Total HIV intra-cellular DNA (TID) of PBMC, CD4, monocytes, and plasmatic viral load (pVL) was analyzed using a commercially available PCR assay. Total DNA of each purified population was isolated by using QIAmp DNA blood mini kit (Qiagen, Hilden, Germany) and then the total TID was PCR amplified using HIV DNA cell kit (Biocentric, 
Bandol, France), and, finally, the amplified viral DNA was quantified to know the exact copies of viral DNA inside PBMC, CD4, monocytes, and plasma.

\subsection{Total Plasma and Cellular Concentration}

Raltegravir and anti-protease cellular concentrations in plasma, PBMC, CD4, and monocytes were measured by HPLC coupled to tandem mass spectrometry (LC-MS/MS; AB Sciex, MA, USA). A $200 \mu \mathrm{L}$ volume of extracting solution containing RLT was added to each isolated cell population and plasma. The lysates of each cell population were then vortexed, sonicated for $30 \mathrm{~min}$, and finally centrifuged at $14,000 \mathrm{rpm}$ for $10 \mathrm{~min}$ at $20^{\circ} \mathrm{C}$. A $200 \mu \mathrm{L}$ volume of supernatant was introduced into a microvial and a $20 \mu \mathrm{L}$ volume was injected into the LC-MS/MS apparatus for drug quantification. $\mathrm{C}_{\text {cell }}$ was expressed in $\mathrm{ng} / \mathrm{mL}$ according to the cell count for all the cell populations.

\subsection{Statistical Method}

Biological parameters were compared from baseline to D90 by using the Wilcoxon signed-rank test, with an alpha risk (two-sided) of 0.05 . Statview ${ }^{\circledR} \mathrm{F}-4.5$ software (SAS Institute Inc., Cary, NC, USA) was used for all analyses. Paired $t$-test was performed using Prism 8 (GraphPad, San Diego, CA, USA). Only significant differences are indicated. The results are expressed as medians (range).

\section{Results}

Six HIV patients who fulfilled the inclusion criteria after extensive screening were enrolled for the study. The main characteristics of the HIV patients including age, sex, duration of HIV, ARV duration and regimen, and their CD4 T-cell counts are described in Table 1.

Table 1. Main characteristics of the 6 included patients. Nadir CD4 T-cells were observed before antiretroviral combinations, while CD4 max. indicates maximal CD4 T-cells value obtained during raltegravir inclusion. HIV follow-up indicates the duration of medical care since the diagnosis of $\mathrm{HIV}$ infection. $\mathrm{ARV}=$ antiretroviral combinations. $\mathrm{LO}=$ lopinavir, $\mathrm{AT}=$ atazanavir, $\mathrm{DA}=$ darunavir, FTC $=$ emtricitabine, $\mathrm{TDF}=$ tenofovir

\begin{tabular}{cccccccc}
\hline Patient No. & Sex & Age & $\begin{array}{c}\text { HIV Follow-Up } \\
\text { (Months) }\end{array}$ & $\begin{array}{c}\text { ARV Duration } \\
\text { (Months) }\end{array}$ & Antiretroviral Regimen & $\begin{array}{c}\text { CD4 } \\
\text { Nadir }\end{array}$ & $\begin{array}{c}\text { CD4 } \\
\text { Max. }\end{array}$ \\
\hline 1 & M & 50 & 18 & 12 & LO + FTC + TDF & 357 & 675 \\
2 & M & 34 & 17 & 10 & LO + FTC + TDF & 252 & 576 \\
3 & M & 31 & 15 & 12 & LO + FTC + TDF & 221 & 897 \\
4 & M & 38 & 34 & 7 & AT + FTC + TDF & 235 & 528 \\
5 & F & 65 & 13 & 12 & LO + FTC + TDF & 205 \\
6 & M & 34 & 26 & 8 & DA + FTC + TDF & 188 & 501 \\
\hline
\end{tabular}

\subsection{Plasmatic and Cellular Viral Load}

The plasmatic viral load remained undetectable during the course of RLT treatment in all patients. In PBMC, the TID median value was 57 (23-421) on day -30 which reduced to $43(10-115)$ on day 60 . On day 90, all 6 patients showed a decreasing trend of PBMC TID as compared to day -30 , but a favorable outcome was seen only in 2 out of 6 patients after RLT administration, throughout the course of the study (Figure 1). We observed a decreasing trend for CD4 T-cell TID, the median value at the beginning being 117 copies/millions of cells (11-480), which reached its minimum load of 27.5 (10-660) on day 60, and 30 (11-1214) on day 90 . The CD4 T-cell TID remained permanently under the cut-off $(<10$ copies/millions of cells) in 4 out of 6 patients after day 60 (Figure 1). For monocytes, the total TID was most of the time under the lower limit of detection, except for 3 time-points in 2 different patients before RLT inclusion (Figure 1). 

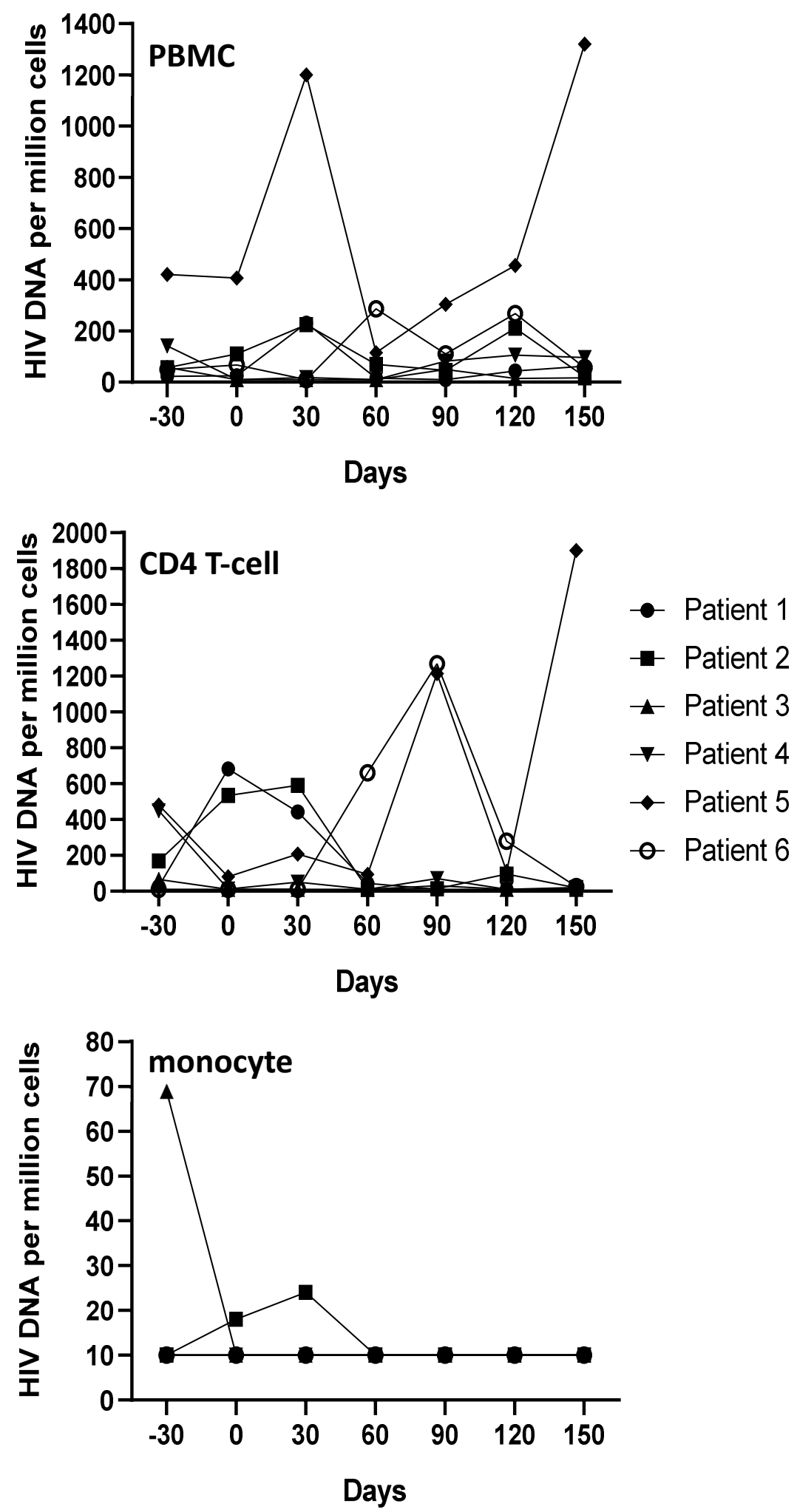

Figure 1. Kinetics of intracellular viral DNA over 7 months of the study protocol. Raltegravir was associated with the current antiretroviral combination from Day 0 to Day 90 (X-axis) with quantification of intracellular HIV DNA per million cells ( $Y$-axis), in peripheral blood mononuclear cells (PBMC), purified CD4 T-cells, and monocytes. A higher quantity of HIV DNA was detected in CD4 T-cells, while monocyte concentrations appeared low to undetectable. Variations of intracellular HIV DNA in PBMC were unpredictable, but it was decreasing in CD4 T-cell subsets, except in patients 5 and 6, as well as in monocytes in which no HIV DNA was detected over Day 60. 


\subsection{T-Cell Count, Activation and Costimulatory Molecules}

The median values for CD4 T-cells at baseline was 451 cells $/ \mathrm{mm}^{3}$ (351-476), which reached 534 cells $/ \mathrm{mm}^{3}$ (433-557) on day 90, $p=0.018$. By the end of the study, the median CD4 T-cell was $516 / \mathrm{mm}^{3}$ (367-762) (Figure 2). The impact of RLT inclusion on absolute CD4 T-cell count is associated with a trend towards a higher percentage from baseline to day 90. At day 150, a paired analysis showed a significant increase in CD4 T-cell percentage as compared to baseline, $p=0.0425$ (Figure S1). Accordingly, Figure 2 suggests that this increase of CD4 T-cells was coupled with a slight decrease of activation as measured through HLA-DR expression. On day 90, the percentage of activated CD4 T-cells was significantly decreased as compared to baseline, $p=0.0484$ (Figure S1).

Absolute CD8 T-cell counts were 677 cells $/ \mathrm{mm}^{3}$ (552-949) at baseline, 686 (458-905) on day 90 and 689 (502-954) on day 150. Despite these stable CD8 T-cell counts, these T-cell subsets also showed a decrease of activated phenotype (Figure 2). On day 90, the paired analysis showed a significant decrease in activated CD8 T-cells percentage, $p=0.0386$ (Figure S1).

Among costimulatory molecules, only CD28 expression showed a coherent increase, particularly on CD8 T-cells (Figure 2 and Figure S1). CD152 positive cell kinetics followed a bumpy curve which ruled out any interpretation (Figure 2 and Figure S1). Finally, the expression of CD80 and CD86 did not show significant variation over the course of the study (data not shown).

\subsection{Proliferation Versus Apoptosis}

We measured the proliferation of T-cells by the expression of the Ki67 marker. For all the 6 patients studied, the value for the proliferation of CD4 T-cells at baseline was $2.1 \%(0.8-5.0)$, which reached $7.2 \%$ (1.5-14.2) on day 90 and $4.9 \%$ on day 150 (1.2-9.4). For CD8 T-cells, the values were $1.6 \%(0.9-2.7), 3.2 \%(0.5-13.2)$, and $2.6 \%(1.2-9.4)$ respectively (Figure 3$)$.

The apoptotic T-cells were recognized as positive for Annexin- $\mathrm{V}$ and negative for propidium iodide. Kinetics of T-cell apoptosis was clearly different between T-cell subsets, being decreased for CD4 T-cells and up-regulated for CD8 T-cells. The median value of apoptotic CD4 T-cells at baseline was 20\% (13-27), which gradually went down to $12.5 \%(2-23)$ on day 90 , being $25 \%(17-33 \%)$ on day 150 . For CD8 T-cells, respective values were $14 \%(1-53), 20 \%(3-56)$, and $43 \%(21-50)$ (Figure 3). Our data clearly shows a positive outcome under RLT, suggesting the biological effect of inclusion, and worsening or returning to baseline after withdrawal.

\subsection{Monocyte Phenotype}

We used CD14 antibodies for the detection of monocytes. It should be considered that monocytes spontaneously expressed HLA-DR, and that cellular activation leads to an up-regulation of membrane expression of this molecule which is detected on the cytofluorometric experiment by the increase of mean intensity fluorescence (MIF). Respective MIF values at baseline, day 90 and day 150 showed a trend towards a down-regulation of HLADR expression, being 32116 (15222-39935), 21875 (3174-38665), and 26188 (18563-48282) respectively $(p=0.08)$. We also tested monocytes for the expression of costimulatory molecule ligands, i.e., B7 molecules, namely CD80 and CD86, which were not altered by RLT inclusion (data not shown).

\subsection{Intracellular Concentrations of Raltegravir}

We looked for the penetration of protease inhibitors and RLT in plasma, PBMC, CD4 T-cells, and monocytes. For protease inhibitors, plasma concentrations of the drugs were in the normal range. Raltegravir was detected in 17/18 time-points in plasma in all the patients (94\%), the median value being $560 \mu \mathrm{g} / \mathrm{mL}(140-4200 \mu \mathrm{g} / \mathrm{mL}$ ) (Figure 4A). In PBMC, RLT was detected in 10/18 time-points (56\%) for all the patients considered, the detectable values being low (Figure 4B). RLT was in a detectable concentration in 6/18 time-points for CD4 T-cells (33\%) (Figure 4C) and for monocytes in 3/18 time-points (Figure 4D). 

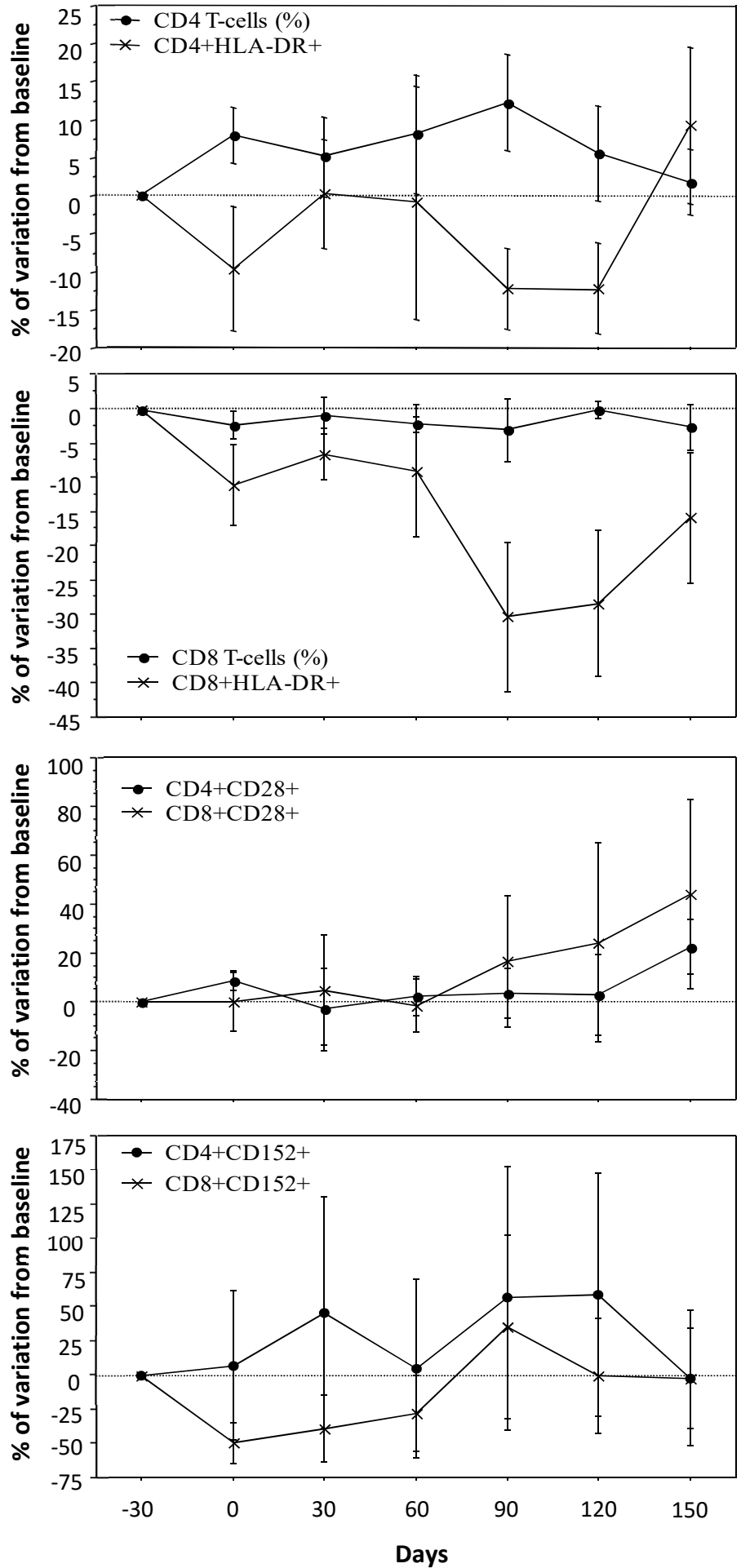

Figure 2. Kinetics of T-cell recovery, activation markers, and costimulatory molecules. T-cell subsets were differently affected during raltegravir inclusion, with a slight increase in CD4 T-cells, contrasting with a trend towards lower CD8 T-cell count. In both cases, HLA-DR positive T-cells were decreasing with rough up-regulation by the end of raltegravir inclusion. Regarding costimulatory molecules, only CD28 positive T-cells showed a regular slight increase, while CD152 expression was not clearly affected. 



Figure 3. Kinetics of T-cell proliferation and T-cell apoptosis. Raltegravir inclusion had clearly 2 different effects on T-cell subsets. For CD4 T-cells, RLT allowed both a slight increase in proliferation, measured using the Ki67 marker, associated with a trend towards lower apoptosis in CD4 T-cells, measured using the Annexin-V marker. Regarding the CD8 T-cell subset, both markers were increased. It should be noted that raltegravir interruption induced bumpy modifications in the percentage of T-cell subsets. 

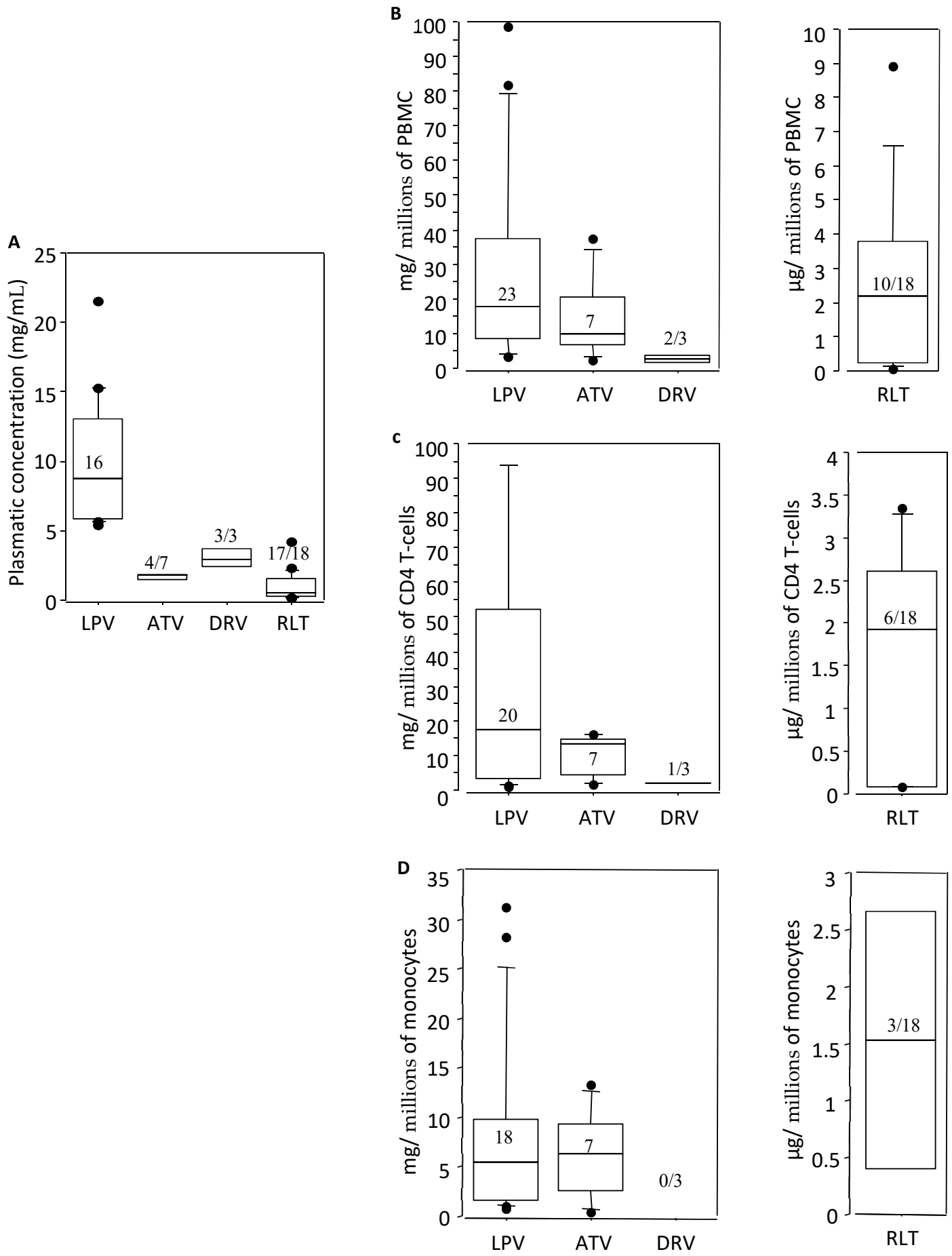

Figure 4. Intracellular drug concentrations in Plasma, PBMC, CD4 T-cells, and monocytes. The cumulative pharmacological data of the 4 drugs analyzed at all the time points. As lopinavir determinations were used to test our methodology, the number of samples is over the expected value. The cellular drug concentration was measured per million cells. The histogram represents only the detected positive values during all time points. Of note, darunavir drug concentration was detected only at (A) 3 time-points in plasma, (B) 2 time-points in PBMC, (C) 1 in CD4 T-cells, and (D) remained undetectable in monocytes. Additionally, most of the time, raltegravir drug concentration was undetectable $(77 \%)$. The number in the box represents the number of positive time-points/total time-points analyzed. LPV = Lopinavir, ATV = Atazanavir, DRV = Darunavir and RLT = Raltegravir A. Plasmatic determinations. B. PBMC determinations. C. CD4 T-cell determinations D. Monocyte determinations. 


\section{Discussion}

In patients living with HIV infection, most dying cells are not infected. It is suggested that T-cell fate is dependent on the micro-environment, including cell-cell interactions [24,31-33]. Additionally, numerous studies have demonstrated the relationship between the efficiency of antiretroviral treatments and CD4 T-cell recovery, the decrease of immune activation, including the downregulation of HLA-DR, CD38, Fas /CD95, and decrease of T-cell apoptosis [14,15,22,34]. However, the positive effect of additional ART treatment has not been clearly demonstrated for patients already with efficient antiretroviral combinations. The occurrence of anti-integrase offered the opportunity to test the effect of RLT inclusion on viral replication and immune restoration.

We report herein that RLT decreased total TID in CD4 T-cells for 4/6 patients, and in monocytes for 2 patients for whom TID was in the detectable range. A decrease of total TID in CD4 T-cells has already been reported when prescribed early in the disease [35]. Additionally, Vallejo et al. reported a significant effect of RLT inclusion in 9 patients who showed a decrease of infectious units per million of resting CD4 T-cells [36]. Our report suggests that the addition of RLT may also decrease total TID in monocytes. Previous studies focused on PBMC have failed to demonstrate any favorable effect of RLT intensification [37-39], suggesting that this non-specific cellular approach could be the reason for missing the virologic impact of this therapy.

An increase in CD4 T-cell count with the inclusion of RLT to combination ART has been already reported, but there are some discrepancies [35-41]. In our study, RLT inclusion was associated with a favorable effect on T-cell homeostasis: CD4 T-cells slightly increased during RLT inclusion in some patients, exhibited a decrease in HLA-DR expression, a late up-regulation of CD28, and a decrease of apoptosis. On the other hand, CD8 T-cells decreased during RLT treatment, exhibited a decrease in HLA-DR expression as well as an up-regulation of CD28. However, no clear impact was seen on CD8 T-cell apoptosis or proliferation. Such discrepancies between T-cell subset fate have been already reported, CD8 T-cells being mostly driven by HIV replication [22,34,40,41].

We also report a trend towards a lower HLA-DR expression on monocytes during RLT treatment, suggesting a down-regulation of cellular activation. As HIV in monocytes was most of the time under the limit of detection, cellular deactivation seems to be independent of the viral reservoir.

Of note, it is important to take into account the kinetics of immunological changes under ART [17,34,40,41], explaining our choice for a short duration of RLT treatment, already known to rapidly inhibit viral replication [27]. Our favorable results might be also related to our method, the patients benefiting from a recent antiretroviral combination and on/off periods of RLT treatment, avoiding non-significant results related to different immunologic backgrounds $[37,38]$. This has also been observed in a comparative trial to different HIV-1 subspecies [42] or previous long-term efficient ART treatment [43].

Finally, RLT intra-cellular concentrations were regularly undetectable or dramatically lower than protease inhibitor concentrations. It should be noted that plasmatic concentrations of both protease inhibitors and RLT were inside the range of expected values, in accordance with previous reports [44]. Results of studies on intra-cellular RLT concentrations are conflicting, with most studies suggesting low intra-cellular distribution and large inter-patient variability, while potential methodological pitfalls might explain these results $[45,46]$. Multiple factors, such as resistance to drugs by T cells and monocytes, cellular mutations, low or sub-optimal dosage, etc. have been associated with low integration of the drug. Comparatively, multiple mutations are required to confer raltegravir resistance in T cells, but a single mutation confers resistance in the monocytes [47-49]. Interestingly, we did not observe any significant difference of RLT concentrations in cellular subsets.

A major limitation of our study is the small number of patients and the limited availability of the sample. This is due to the strict inclusion criteria followed by extensive screening of the patients. Therefore, further studies are needed, to more precisely determine the kinetics of RLT in HIV cellular targets in a larger patient cohort. 
In conclusion, in patients with a mild immune response to a recent first-line efficient antiretroviral combination, RLT inclusion decreases total intra-cellular HIV DNA in virally targeted cells despite low concentrations of intracellular drugs and is associated with an improvement of T-cells homeostasis.

Supplementary Materials: The following are available online at https:/ / www.mdpi.com/article/ 10.3390/cells11020208/s1, Figure S1: The median values of the percentage of CD4 T-cells, CD8 T-cells, and the expression of HLA-DR, CD28, and CD152 by CD4 and CD8 T-cells at different time points analyzed by flow cytometer. Error bars represent the range of the values.

Author Contributions: G.K. conceptualized, designed, and performed experiments, interpreted results, and wrote the manuscript. J.C.-D. did the virological analysis, R.G. did the pharmacological analysis, F.D.S.-G. and E.C. arranged for the patients and the blood samples, P.-M.R. arranged the samples, conceptualized, designed experiments, interpreted results, and wrote the manuscript. All authors have read and agreed to the published version of the manuscript.

Funding: The work was supported by grants from Infectiopôle Sud and Recherche Et Développement en Pathologies Infectieuses et Tropicales (REDPIT), France and partially from Merck Sharp and Dohme.

Institutional Review Board Statement: The study was conducted according to the guidelines of the Declaration of Helsinki and approved by the Institutional Review Board of the Infectious Disease Department of Nice University Hospital, Nice, France.

Informed Consent Statement: Informed consent was obtained from all subjects involved in the study.

Data Availability Statement: The data presented in this study are available on request from the corresponding author.

Acknowledgments: The authors wish to acknowledge the Infectiologie unit, Hopital l'Archet 1, Nice, France for providing the sample and the study participants.

Conflicts of Interest: The authors declare no conflict of interest.

\section{References}

1. Hammer, S.M.; Saag, M.S.; Schechter, M.; Montaner, J.S.; Schooley, R.T.; Jacobsen, D.M.; Thompson, M.A.; Carpenter, C.C.; Fischl, M.A.; Gazzard, B.G.; et al. Treatment for adult HIV infection: 2006 recommendations of the International AIDS Society-USA panel. JAMA 2006, 296, 827-843. [CrossRef] [PubMed]

2. Le, T.; Wright, E.J.; Smith, D.M.; He, W.; Catano, G.; Okulicz, J.F.; Young, J.A.; Clark, R.A.; Richman, D.D.; Little, S.J.; et al. Enhanced CD4+ T-cell recovery with earlier HIV-1 antiretroviral therapy. N. Engl. J. Med. 2013, 368, 218-230. [CrossRef] [PubMed]

3. Smith, C.J.; Sabin, C.A.; Lampe, F.C.; Kinloch-de-Loes, S.; Gumley, H.; Carroll, A.; Prinz, B.; Youle, M.; Johnson, M.A.; Phillips, A.N. The potential for CD4 cell increases in HIV-positive individuals who control viraemia with highly active antiretroviral therapy. AIDS 2003, 17, 963-969. [CrossRef]

4. $\quad$ French, M.A.; King, M.S.; Tschampa, J.M.; da Silva, B.A.; Landay, A.L. Serum immune activation markers are persistently increased in patients with HIV infection after 6 years of antiretroviral therapy despite suppression of viral replication and reconstitution of CD4+ T cells. J. Infect. Dis. 2009, 200, 1212-1215. [CrossRef] [PubMed]

5. Cantero-Perez, J.; Grau-Exposito, J.; Serra-Peinado, C.; Rosero, D.A.; Luque-Ballesteros, L.; Astorga-Gamaza, A.; Castellvi, J.; Sanhueza, T.; Tapia, G.; Lloveras, B.; et al. Resident memory T cells are a cellular reservoir for HIV in the cervical mucosa. Nat. Commun. 2019, 10, 4739. [CrossRef]

6. Cassol, E.; Alfano, M.; Biswas, P.; Poli, G. Monocyte-derived macrophages and myeloid cell lines as targets of HIV-1 replication and persistence. J. Leukoc. Biol. 2006, 80, 1018-1030. [CrossRef] [PubMed]

7. Chun, T.W.; Finzi, D.; Margolick, J.; Chadwick, K.; Schwartz, D.; Siliciano, R.F. In vivo fate of HIV-1-infected T cells: Quantitative analysis of the transition to stable latency. Nat. Med. 1995, 1, 1284-1290. [CrossRef] [PubMed]

8. Lambotte, O.; Deiva, K.; Tardieu, M. HIV-1 persistence, viral reservoir, and the central nervous system in the HAART era. Brain Pathol. 2003, 13, 95-103. [CrossRef] [PubMed]

9. Finzi, D.; Hermankova, M.; Pierson, T.; Carruth, L.M.; Buck, C.; Chaisson, R.E.; Quinn, T.C.; Chadwick, K.; Margolick, J.; Brookmeyer, R.; et al. Identification of a reservoir for HIV-1 in patients on highly active antiretroviral therapy. Science 1997, 278, 1295-1300. [CrossRef]

10. Pomerantz, R.J. Reservoirs of human immunodeficiency virus type 1: The main obstacles to viral eradication. Clin. Infect. Dis. 2002, 34, 91-97. [CrossRef]

11. Siliciano, J.D.; Siliciano, R.F. In Vivo Dynamics of the Latent Reservoir for HIV-1: New Insights and Implications for Cure. Annu Rev. Pathol. 2021. [CrossRef] 
12. Moar, P.; Sushmita, K.; Kateriya, S.; Tandon, R. Transcriptional profiling indicates cAMP-driven reversal of HIV latency in monocytes occurs via transcription factor SP-1. Virology 2020, 542, 40-53. [CrossRef] [PubMed]

13. Pakker, N.G.; Notermans, D.W.; de Boer, R.J.; Roos, M.T.; de Wolf, F.; Hill, A.; Leonard, J.M.; Danner, S.A.; Miedema, F.; Schellekens, P.T. Biphasic kinetics of peripheral blood T cells after triple combination therapy in HIV-1 infection: A composite of redistribution and proliferation. Nat. Med. 1998, 4, 208-214. [CrossRef] [PubMed]

14. Stone, S.F.; Price, P.; French, M.A. Dysregulation of CD28 and CTLA-4 expression by CD4 T cells from previously immunodeficient HIV-infected patients with sustained virological responses to highly active antiretroviral therapy. HIV Med. 2005, 6, 278-283. [CrossRef] [PubMed]

15. Kestens, L.; Vanham, G.; Vereecken, C.; Vandenbruaene, M.; Vercauteren, G.; Colebunders, R.L.; Gigase, P.L. Selective increase of activation antigens HLA-DR and CD38 on CD4 + CD45RO + T lymphocytes during HIV-1 infection. Clin. Exp. Immunol. 1994, 95, 436-441. [CrossRef]

16. Leng, Q.; Bentwich, Z.; Magen, E.; Kalinkovich, A.; Borkow, G. CTLA-4 upregulation during HIV infection: Association with anergy and possible target for therapeutic intervention. AIDS 2002, 16, 519-529. [CrossRef]

17. Pakker, N.G.; Kroon, E.D.; Roos, M.T.; Otto, S.A.; Hall, D.; Wit, F.W.; Hamann, D.; van der Ende, M.E.; Claessen, F.A.; Kauffmann, R.H.; et al. Immune restoration does not invariably occur following long-term HIV-1 suppression during antiretroviral therapy. INCAS Study Group. AIDS 1999, 13, 203-212. [CrossRef]

18. Saukkonen, J.J.; Kornfeld, H.; Berman, J.S. Expansion of a CD8+ CD28-cell population in the blood and lung of HIV-positive patients. J. Acquir. Immune Defic. Syndr. 1993, 6, 1194-1204.

19. Vingerhoets, J.H.; Vanham, G.L.; Kestens, L.L.; Penne, G.G.; Colebunders, R.L.; Vandenbruaene, M.J.; Goeman, J.; Gigase, P.L.; De Boer, M.; Ceuppens, J.L. Increased cytolytic T lymphocyte activity and decreased B7 responsiveness are associated with CD28 down-regulation on CD8+ T cells from HIV-infected subjects. Clin. Exp. Immunol. 1995, 100, 425-433. [CrossRef]

20. Borthwick, N.J.; Bofill, M.; Gombert, W.M.; Akbar, A.N.; Medina, E.; Sagawa, K.; Lipman, M.C.; Johnson, M.A.; Janossy, G. Lymphocyte activation in HIV-1 infection. II. Functional defects of CD28- T cells. AIDS 1994, 8, 431-441. [CrossRef]

21. Kammerer, R.; Iten, A.; Frei, P.C.; Burgisser, P. Expansion of T cells negative for CD28 expression in HIV infection. Relation to activation markers and cell adhesion molecules, and correlation with prognostic markers. Med. Microbiol. Immunol. 1996, 185, 19-25. [CrossRef]

22. Gougeon, M.L.; Lecoeur, H.; Dulioust, A.; Enouf, M.G.; Crouvoiser, M.; Goujard, C.; Debord, T.; Montagnier, L. Programmed cell death in peripheral lymphocytes from HIV-infected persons: Increased susceptibility to apoptosis of CD4 and CD8 T cells correlates with lymphocyte activation and with disease progression. J. Immunol. 1996, 156, 3509-3520.

23. Cavert, W.; Notermans, D.W.; Staskus, K.; Wietgrefe, S.W.; Zupancic, M.; Gebhard, K.; Henry, K.; Zhang, Z.Q.; Mills, R.; McDade, H.; et al. Kinetics of response in lymphoid tissues to antiretroviral therapy of HIV-1 infection. Science 1997, 276, 960-964. [CrossRef] [PubMed]

24. Demeter, L.M.; Bosch, R.J.; Coombs, R.W.; Fiscus, S.; Bremer, J.; Johnson, V.A.; Erice, A.; Jackson, J.B.; Spector, S.A.; Squires, K.M.; et al. Detection of replication-competent human immunodeficiency virus type 1 (HIV-1) in cultures from patients with levels of HIV-1 RNA in plasma suppressed to less than 500 or 50 copies per milliliter. J. Clin. Microbiol. 2002, 40, 2089-2094. [CrossRef] [PubMed]

25. Sharkey, M.E.; Teo, I.; Greenough, T.; Sharova, N.; Luzuriaga, K.; Sullivan, J.L.; Bucy, R.P.; Kostrikis, L.G.; Haase, A.; Veryard, C.; et al. Persistence of episomal HIV-1 infection intermediates in patients on highly active anti-retroviral therapy. Nat. Med. 2000, 6, 76-81. [CrossRef] [PubMed]

26. Eron, J.J.; Young, B.; Cooper, D.A.; Youle, M.; Dejesus, E.; Andrade-Villanueva, J.; Workman, C.; Zajdenverg, R.; Fatkenheuer, G.; Berger, D.S.; et al. Switch to a raltegravir-based regimen versus continuation of a lopinavir-ritonavir-based regimen in stable HIV-infected patients with suppressed viraemia (SWITCHMRK 1 and 2): Two multicentre, double-blind, randomised controlled trials. Lancet 2010, 375, 396-407. [CrossRef]

27. Hicks, C.; Gulick, R.M. Raltegravir: The first HIV type 1 integrase inhibitor. Clin. Infect. Dis. 2009, 48, 931-939. [CrossRef]

28. Lennox, J.L.; DeJesus, E.; Lazzarin, A.; Pollard, R.B.; Madruga, J.V.; Berger, D.S.; Zhao, J.; Xu, X.; Williams-Diaz, A.; Rodgers, A.J.; et al. Safety and efficacy of raltegravir-based versus efavirenz-based combination therapy in treatment-naive patients with HIV-1 infection: A multicentre, double-blind randomised controlled trial. Lancet 2009, 374, 796-806. [CrossRef]

29. Massanella, M.; Negredo, E.; Puig, J.; Puertas, M.C.; Buzon, M.J.; Perez-Alvarez, N.; Carrillo, J.; Clotet, B.; Martinez-Picado, J.; Blanco, J. Raltegravir intensification shows differing effects on CD8 and CD4 T cells in HIV-infected HAART-suppressed individuals with poor CD4 T-cell recovery. AIDS 2012, 26, 2285-2293. [CrossRef] [PubMed]

30. Santinelli, L.; Ceccarelli, G.; Borrazzo, C.; Celani, L.; Pavone, P.; Innocenti, G.P.; Spagnolello, O.; Fimiani, C.; Ceci, F.; Di Sora, F.; et al. Real word outcomes associated with use of raltegravir in older people living with HIV: Results from the 60 months follow-up of the RAL-age cohort. Expert Rev. Anti Infect. Ther. 2020, 18, 485-492. [CrossRef]

31. Badley, A.D.; McElhinny, J.A.; Leibson, P.J.; Lynch, D.H.; Alderson, M.R.; Paya, C.V. Upregulation of Fas ligand expression by human immunodeficiency virus in human macrophages mediates apoptosis of uninfected T lymphocytes. J. Virol. 1996, 70, 199-206. [CrossRef] [PubMed]

32. Finkel, T.H.; Tudor-Williams, G.; Banda, N.K.; Cotton, M.F.; Curiel, T.; Monks, C.; Baba, T.W.; Ruprecht, R.M.; Kupfer, A. Apoptosis occurs predominantly in bystander cells and not in productively infected cells of HIV- and SIV-infected lymph nodes. Nat. Med. 1995, 1, 129-134. [CrossRef] 
33. Garaci, E.; Aquaro, S.; Lapenta, C.; Amendola, A.; Spada, M.; Covaceuszach, S.; Perno, C.F.; Belardelli, F. Anti-nerve growth factor $\mathrm{Ab}$ abrogates macrophage-mediated HIV-1 infection and depletion of CD4+ T lymphocytes in hu-SCID mice. Proc. Natl. Acad. Sci. USA 2003, 100, 8927-8932. [CrossRef]

34. Roger, P.M.; Breittmayer, J.P.; Durant, J.; Sanderson, F.; Ceppi, C.; Brignone, C.; Cua, E.; Clevenbergh, P.; Fuzibet, J.G.; Pesce, A.; et al. Early CD4(+) T cell recovery in human immunodeficiency virus-infected patients receiving effective therapy is related to a down-regulation of apoptosis and not to proliferation. J. Infect. Dis. 2002, 185, 463-470. [CrossRef]

35. Koelsch, K.K.; Boesecke, C.; McBride, K.; Gelgor, L.; Fahey, P.; Natarajan, V.; Baker, D.; Bloch, M.; Murray, J.M.; Zaunders, J.; et al. Impact of treatment with raltegravir during primary or chronic HIV infection on RNA decay characteristics and the HIV viral reservoir. AIDS 2011, 25, 2069-2078. [CrossRef] [PubMed]

36. Vallejo, A.; Gutierrez, C.; Hernandez-Novoa, B.; Diaz, L.; Madrid, N.; Abad-Fernandez, M.; Dronda, F.; Perez-Elias, M.J.; Zamora, J.; Munoz, E.; et al. The effect of intensification with raltegravir on the HIV-1 reservoir of latently infected memory CD4 T cells in suppressed patients. AIDS 2012, 26, 1885-1894. [CrossRef]

37. Delaugerre, C.; Charreau, I.; Braun, J.; Nere, M.L.; de Castro, N.; Yeni, P.; Ghosn, J.; Aboulker, J.P.; Molina, J.M.; Simon, F.; et al. Time course of total HIV-1 DNA and 2-long-terminal repeat circles in patients with controlled plasma viremia switching to a raltegravir-containing regimen. AIDS 2010, 24, 2391-2395. [CrossRef]

38. Hatano, H.; Hayes, T.L.; Dahl, V.; Sinclair, E.; Lee, T.H.; Hoh, R.; Lampiris, H.; Hunt, P.W.; Palmer, S.; McCune, J.M.; et al. A randomized, controlled trial of raltegravir intensification in antiretroviral-treated, HIV-infected patients with a suboptimal CD4+ T cell response. J. Infect. Dis. 2011, 203, 960-968. [CrossRef]

39. Lam, Y.M.; McBride, K.L.; Amin, J.; Cordery, D.V.; Kelleher, A.D.; Cooper, D.A.; Koelsch, K.K. Switching virally suppressed, treatment-experienced patients to a raltegravir-containing regimen does not alter levels of HIV-1 DNA. PLoS ONE 2012, 7, e31990. [CrossRef] [PubMed]

40. Buzon, M.J.; Massanella, M.; Llibre, J.M.; Esteve, A.; Dahl, V.; Puertas, M.C.; Gatell, J.M.; Domingo, P.; Paredes, R.; Sharkey, M.; et al. HIV-1 replication and immune dynamics are affected by raltegravir intensification of HAART-suppressed subjects. Nat. Med. 2010, 16, 460-465. [CrossRef] [PubMed]

41. Catalfamo, M.; Di Mascio, M.; Hu, Z.; Srinivasula, S.; Thaker, V.; Adelsberger, J.; Rupert, A.; Baseler, M.; Tagaya, Y.; Roby, G.; et al. HIV infection-associated immune activation occurs by two distinct pathways that differentially affect CD4 and CD8 T cells. Proc. Natl. Acad. Sci. USA 2008, 105, 19851-19856. [CrossRef] [PubMed]

42. Rockstroh, J.K.; Teppler, H.; Zhao, J.; Sklar, P.; Miller, M.D.; Harvey, C.M.; Strohmaier, K.M.; Leavitt, R.Y.; Nguyen, B.Y. Clinical efficacy of raltegravir against B and non-B subtype HIV-1 in phase III clinical studies. AIDS 2011, 25, 1365-1369. [CrossRef] [PubMed]

43. Chege, D.; Kovacs, C.; la Porte, C.; Ostrowski, M.; Raboud, J.; Su, D.; Kandel, G.; Brunetta, J.; Kim, C.J.; Sheth, P.M.; et al. Effect of raltegravir intensification on HIV proviral DNA in the blood and gut mucosa of men on long-term therapy: A randomized controlled trial. AIDS 2012, 26, 167-174. [CrossRef]

44. Molto, J.; Valle, M.; Back, D.; Cedeno, S.; Watson, V.; Liptrott, N.; Egan, D.; Miranda, C.; Barbanoj, M.J.; Clotet, B. Plasma and intracellular (peripheral blood mononuclear cells) pharmacokinetics of once-daily raltegravir (800 milligrams) in HIV-infected patients. Antimicrob. Agents Chemother. 2011, 55, 72-75. [CrossRef]

45. Fayet Mello, A.; Buclin, T.; Franc, C.; Colombo, S.; Cruchon, S.; Guignard, N.; Biollaz, J.; Telenti, A.; Decosterd, L.A.; Cavassini, M. Cell disposition of raltegravir and newer antiretrovirals in HIV-infected patients: High inter-individual variability in raltegravir cellular penetration. J. Antimicrob. Chemother. 2011, 66, 1573-1581. [CrossRef]

46. Jackson, A.; Watson, V.; Back, D.; Khoo, S.; Liptrott, N.; Egan, D.; Gedela, K.; Higgs, C.; Abbas, R.; Gazzard, B.; et al. Plasma and intracellular pharmacokinetics of darunavir/ritonavir once daily and raltegravir once and twice daily in HIV-infected individuals. J. Acquir. Immune Defic. Syndr. 2011, 58, 450-457. [CrossRef]

47. Asahchop, E.L.; Meziane, O.; Mamik, M.K.; Chan, W.F.; Branton, W.G.; Resch, L.; Gill, M.J.; Haddad, E.; Guimond, J.V.; Wainberg, M.A.; et al. Reduced antiretroviral drug efficacy and concentration in HIV-infected microglia contributes to viral persistence in brain. Retrovirology 2017, 14, 47. [CrossRef] [PubMed]

48. Campbell, J.H.; Hearps, A.C.; Martin, G.E.; Williams, K.C.; Crowe, S.M. The importance of monocytes and macrophages in HIV pathogenesis, treatment, and cure. AIDS 2014, 28, 2175-2187. [CrossRef] [PubMed]

49. Scopelliti, F.; Pollicita, M.; Ceccherini-Silberstein, F.; Di Santo, F.; Surdo, M.; Aquaro, S.; Perno, C.F. Comparative antiviral activity of integrase inhibitors in human monocyte-derived macrophages and lymphocytes. Antivir. Res. 2011, 92, 255-261. [CrossRef] 